\title{
The Service-Dominant Ecosystem: Mapping a Service Dominant Strategy to a Product-Service Ecosystem
}

\author{
Egon Lüftenegger, Marco Comuzzi, and Paul Grefen \\ School of Industrial Engineering, Eindhoven University of Technology \\ P.O. Box 513, 5600 MB Eindhoven, The Netherlands \\ \{e.r.luftenegger,m.comuzzi,p.w.p.j.grefen\} atue.nl
}

\begin{abstract}
Nowadays product-oriented companies are facing the need to focus on the service rather than the product alone. By following a Service-Dominant Strategy, we need to focus on the ecosystem embodying the collaboration to provide such a service. This collaborative perspective on value creation and value sharing is the foundation for designing new business models within the ecosystem. We take the lessons learned in the car-leasing domain on the development of a Service-Dominant Strategy to design a tool supporting the transition from product focus to Product-Service ecosystems.
\end{abstract}

Keywords: service dominant strategy, service dominant logic, servitization, product, service, ecosystem, value.

\section{Introduction}

Nowadays, it is widely assumed that manufacturing firms need to offer services and solutions delivered through their products to survive in developed countries [1]. Moreover, the shift from goods to service has been in process since the early 1990s as the role of manufacturers producing and selling products in value chain has become less remunerative [2]. This shift has been driven by external and internal factors. Examples of external factors are new possibilities of business growth in mature industries by extending the range of manufacturers towards services and customer demands on solutions. Example of internal factors are financial savings and revenues, where companies such as Xerox shift from producing and selling copy machines to document management systems solutions, perceiving service-orientation as a survival strategy [3].

The Servitization of manufacturing is a term first mentioned as a competitive manufacturing strategy by adding services to products to create value [4]. Manufacturers have been going downstream the value chain by focusing on activities (such as financing, maintenance and spare-parts) by looking on how the product is being used by the customers at the end of value chain [2]. This results in an integrated productservice offering by the manufacturer. However, this product-service integration by manufacturers is just seen as a linear production process where the manufacturer adds value to its products through services [5].

The organizational shift from goods-centric towards a service-centric organization is highly relevant for the development of the so-called "Service Science". "Service Science 
is an emerging interdisciplinary field of inquiry that focuses on fundamental science, models, theories and applications to drive service innovation, competition, and wellbeing through co-creation of value" [6]. The change from goods towards solutions is recognized as an academic research priority for the science of services [6].

The challenges of developing value propositions for service-goods offerings is being recognized as a tremendous opportunity for practitioners and researchers in the service arena. This owes to Goods-Dominant organizations rarely recognizing the need to develop goods-service value propositions. Furthermore, research and management tools development has been focusing on the goods-dominant mindset within the value chain. Service-focused tools built under a service-dominant mindset are however needed by the service science research field to foster adoption by practitioners [6]. Hence, we see a research opportunity for a management tool constructed on the service-dominant mindset with a focus on the service-product ecosystem as a whole rather than the traditional value chain.

We found especially interesting the shift from product to service in the asset-finance domain, particularly in car leasing where lessors rely on vendor assets to offer their service. Moreover, the pure focus on the assets lifecycle as a revenue source seems to be no longer enough to sustain the business in a Service-Dominant business landscape.

In this paper we build on our previous work on Service-Dominant strategy definition [7]. We devise a tool to map a Service-Dominant strategy into a complex ecosystem able to support the above-mentioned manufacturers' transformation from products to service solutions providers. We built our tool using our experience on such a transition in the carleasing domain. Our tool overcomes the typical value chain-based view on servitization by allowing the identification of complex networks of actors, activities, and value propositions constituting the product-service ecosystem.

The paper is structured as follows: In Section 2, we introduce the Service-Dominant Strategy. In section 3, we establish a transition to the ecosystem concept. In Section 4, we visualize the Service Dominant Ecosystems. In Section 5, we discuss the results our lessons with the car-leasing domain. Finally, we draw our conclusions and briefly outline future work.

\section{Background the Service-Dominant Strategy}

In this section we focus on the Service-Dominant Strategy as a plan to acquire and deploy the service-dominant mindset within the organization and as a new way of doing business [7], [8].

Nowadays, the shift from product to service is being conceptualized as a mindset shift from Goods-Dominant (G-D) Logic towards Service-Dominant (S-D) Logic. The G-D Logic is the traditional manufacturing logic that focuses on the value chain: a product is produced and then value is added through services. The S-D logic focuses on the benefits of adding services, where products are just a mechanism for service provision. This mindset focuses on the value networks and value propositions [9].

The mandate of the S-D Strategy is to focus on operant resources and service flows, to find innovative ways to integrate them for service provision. These service flows can be part of the organization or outside the organization, involving other actors of the ecosystem. Furthermore, Information Technologies (IT) can support this service-orientation by the management and integration of service flows within the service ecosystem. 
Our strategic focus is on the value-in-use, where the value is seen as a benefit for the customer and not on the product or services. For instance, when a customer purchases a driller the value is on the job of making holes by using the driller for the buyer and the value for the seller derived from selling the driller. This is known in the S-D Strategy as value co-creation.

Flexible organizational boundaries are required to foster the collaboration within the ecosystem. Moreover, the interactions of actors within the network are bidirectional, i.e. a consumer and a producer at the same time can contribute to value creation within the ecosystem. This co-production is achieved by empowering the actors with the right tools to participate actively in the ecosystem.

The ecosystem orchestrator integrates the service flows from different actors resulting from their co-production activities by offering the integrated value proposition at a price that includes the risk of their collaborators. Furthermore, the benefits should be ethically shared among the participants. This does not include only financial benefits, but other forms of benefit such as knowledge acquisition.

Once this strategic view is embraced, we need to take the steps to facilitate the design and communicate businesses following a Service-Dominant strategy.

\section{Transitioning from Service-Dominant Strategy towards an Ecosystem}

A S-D Strategy sets the plan and the perspective on doing business. Moreover, strategy is a set of choices on how the business is being conceptualized. However, to operationalize the strategy we need to reflect these choices into business models.

The business model concept is used to describe value creation and value appropriation. Current business model conceptualizations are focused at the value chain level rather than the network level. This follows the G-D Logic foundation on the manufacturing industry, from raw material, to production of goods and then value added services. By following a S-D Strategy, we need to look at the collaborations between actors to co-create value. This view requires focusing on the value network and the company ecosystem rather than the internal perspective on the value chain. Hence, we start the operationalization of the Service-Dominant Strategy towards business models at the ecosystem level.

We can think on the ecosystem as a collaborative business model tool, where we focus on value creation and appropriation at the network level, beyond the boundaries of one organization. Furthermore, we can view the ecosystem as the operationalization of the S-D strategy by establishing our value network of value propositions as a product-service system [10].

Servitization is also linked to the Product-Service System (PSS) literature [5]. The PSS concept arises as the embracement of a service-led strategy to differentiate from companies that offer low cost products. A PSS is defined as 'an integrated combination of products and services that deliver value in use' [11]. Furthermore, these integrated solutions can be viewed as integrated service-product combinations, tailored to create desired outcomes for the customer [12]. A PSS emphasizes the value in use as a solution, rather than the sale of a product [11]. For instance, the value in use can be seen in companies like Rolls-Royce, which deliver power-by-the-hour to airlines as a combination of jet engines (products) with monitoring (services) [12]. 
In contrast with manufacturing companies, service-based companies are more flexible towards a multivendor system tailored to customers' need. [12]. However, multivendor companies that rely on adding value form vendor's assets with services could easily face disruption on their business if the ecosystem is not defined and managed properly. Hence, we need to establish an ecosystem to see how a company should collaborate with different actors within a value network.

\section{The Service-Dominant Ecosystem}

In this section, we present a tool to design and communicate ecosystems derived from a S-D Strategy. This strategic view suggests focusing on collaborations at the network level of actors. We conceptualize the ecosystem as follows: Firstly, an ecosystem comprises heterogeneous entities such as businesses, firms, and customers, i.e. the ecosystem actors. Secondly, these entities interact with each other to achieve shared goals, i.e. value co-creation. Thirdly, these entities can be viewed as socio-economic actors, connected through value propositions. Finally, entities perform actions aimed at reaching desired outcomes, such as mutual value creation through co-produced solutions and experiences [13].

We further elaborate the service ecosystem concept by developing an artifact to describe and communicate the ecosystem level driven by a S-D strategy, that is, the Service-Dominant Ecosystem. The resulting ecosystem is presented in Figure 1 as concentric circles and slices. Each actor of the ecosystem is represented as a slice of the concentric circles connected to the inner circle that represents the common cocreation goal of the ecosystem. From outside in, the concentric circles are used to represent the ecosystem collaboration of each actor as follows: firstly, the cost and benefits of each actor; secondly, the co-production activities of performed by each actor and thirdly, each actor's value proposition.

As shown in Figure 1, we describe the Service-Dominant Ecosystem as a networked perspective requiring an Actor-to-Actor perspective focused on value cocreation by integrating each actor's value propositions. Moreover, each actor has an active role in the ecosystem by performing activities that are reflected as costs and benefits for each one. We first exemplify the elements using the Spotify ecosystem to describe each element of the S-D ecosystem as follows.

Value Co-creation. The ecosystem goal is value co-creation defined in terms of value-in-use. We define the core of the ecosystem as the experience or solution that we want to co-create with the ecosystem actors. For instance, the Spotify ecosystem cocreates a music listening experience.

Ecosystem Actors. The S-D Logic aims at overcoming the producer and consumer divide by pointing out an Actor-to-Actor (A2A) perspective emphasizing the heterogeneity of business entities. Such an A2A focus drives away the traditional manufacturing logic based on the liner process of value creation driven by the value chain [13], [14]. For instance, in the Spotify ecosystem, besides the company we can distinguish free users, paying users, record labels, original equipment manufacturers (OEMs) and application developers. 


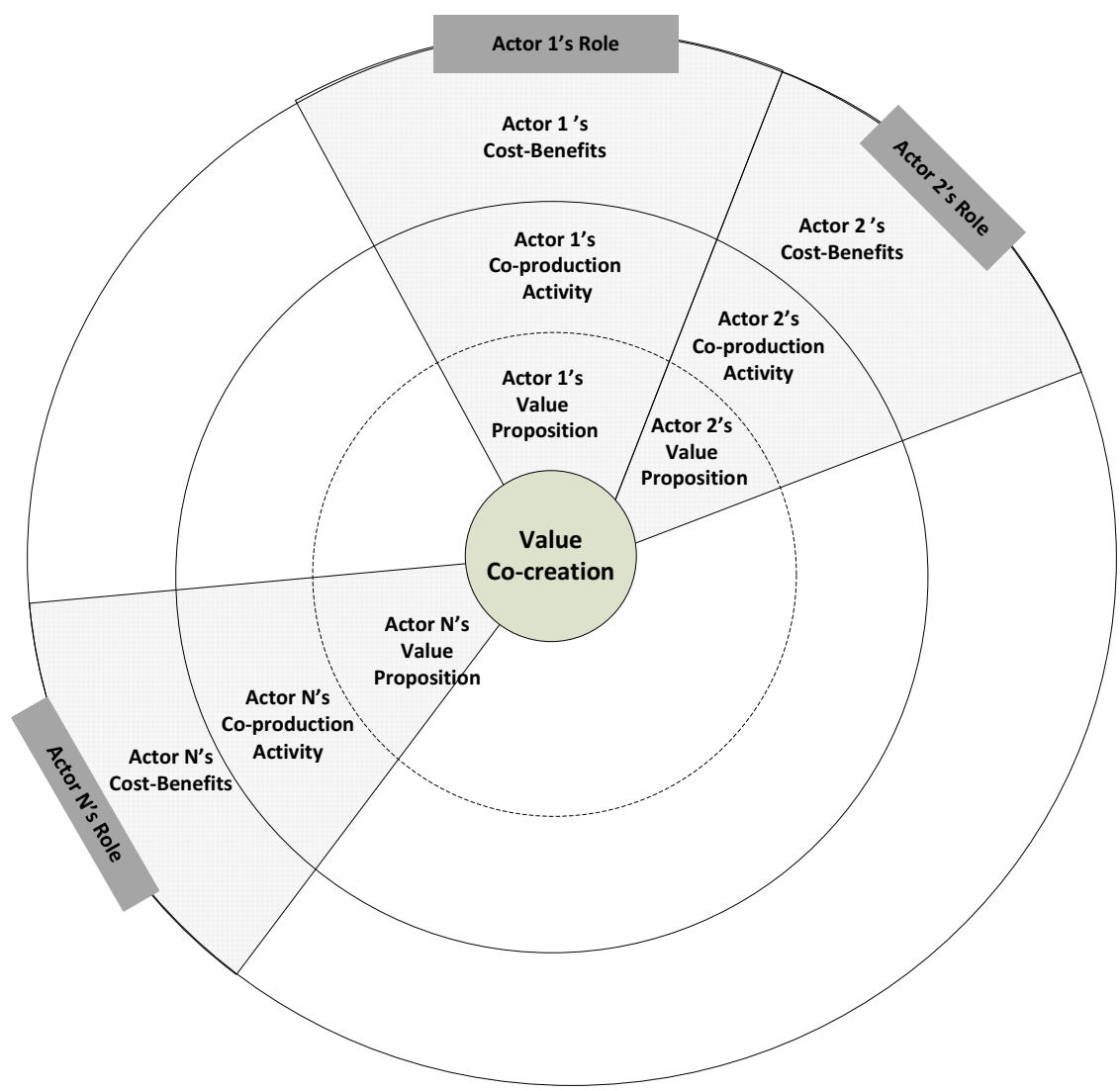

Fig. 1. The Service-Dominant Ecosystem

Actors Value Propositions. The value propositions is what each actor delivers to the ecosystem. This can be thought as a network effect, where the value proposition of one actor enhances the overall value for the same or other group of actors. These are known as same-side and cross-side network effects, respectively. For instance, in the Spotify ecosystem a same-side network effect is achieved when more users bring more content to other users into the ecosystem and a cross-side network effect is achieved when music content generated by application developers creates value for the users by improving listening choices [15].

Co-production Activities. Each actor performs activities in the ecosystem to deliver value propositions. For instance, in the Spotify ecosystem, users participate in the ecosystem by creating and sharing playlists, developers participate by creating music applications, and record labels participate by providing their music libraries.

Costs-Benefit Sharing. The actors incurs in costs and obtains benefits by participating into the ecosystem. These costs and benefits are driven by the need to share benefits and establish the cost of the actors in the collaboration. For instance, in the Spotify ecosystem the record labels incur in cost of signing artists and get the benefits of monetary license fees. 
In Figure 2, we analyze the ecosystem of Spotify to illustrate how our tool works. The goal of the ecosystem as value-in-use is represented at the center of the figure, in this case the music listening ecosystem. The actors are identified as a slice of the circle, where we can identify the orchestrator as Spotify, partners such as record labels and advertisers, complementors such as original equipment manufacturers (OEMs) and application developers. At last we have prosumers like free and premium users. Each actor performs a co-production activity, for instance the free premium users create and share playlists, and OEMs provide connected hardware. The value propositions are presented as increased value on the ecosystems, for instance the value proposition at ecosystem level is to provide more access points to listen music.
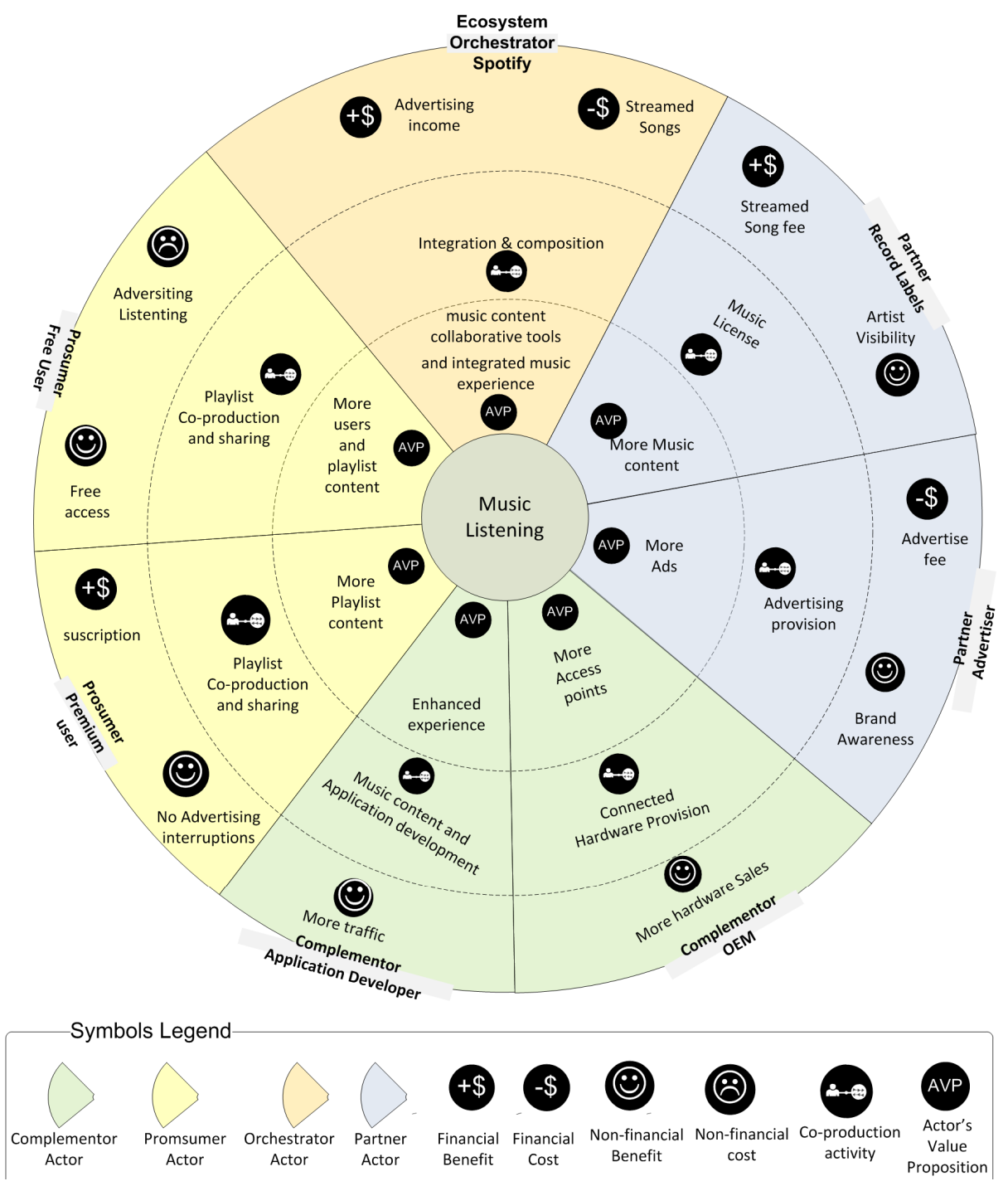

Fig. 2. The Service-Dominant Ecosystem of Spotify 
In the next section we discuss the lesson learned by applying our artifact to a more complex case in the mobility scenario (car leasing).

\section{Defining the Service Ecosystem in Mobility}

We have been collaborating with the biggest car leasing company in the Netherlands to support their transition from the product focus, e.g. leasing cars, towards a service focus,
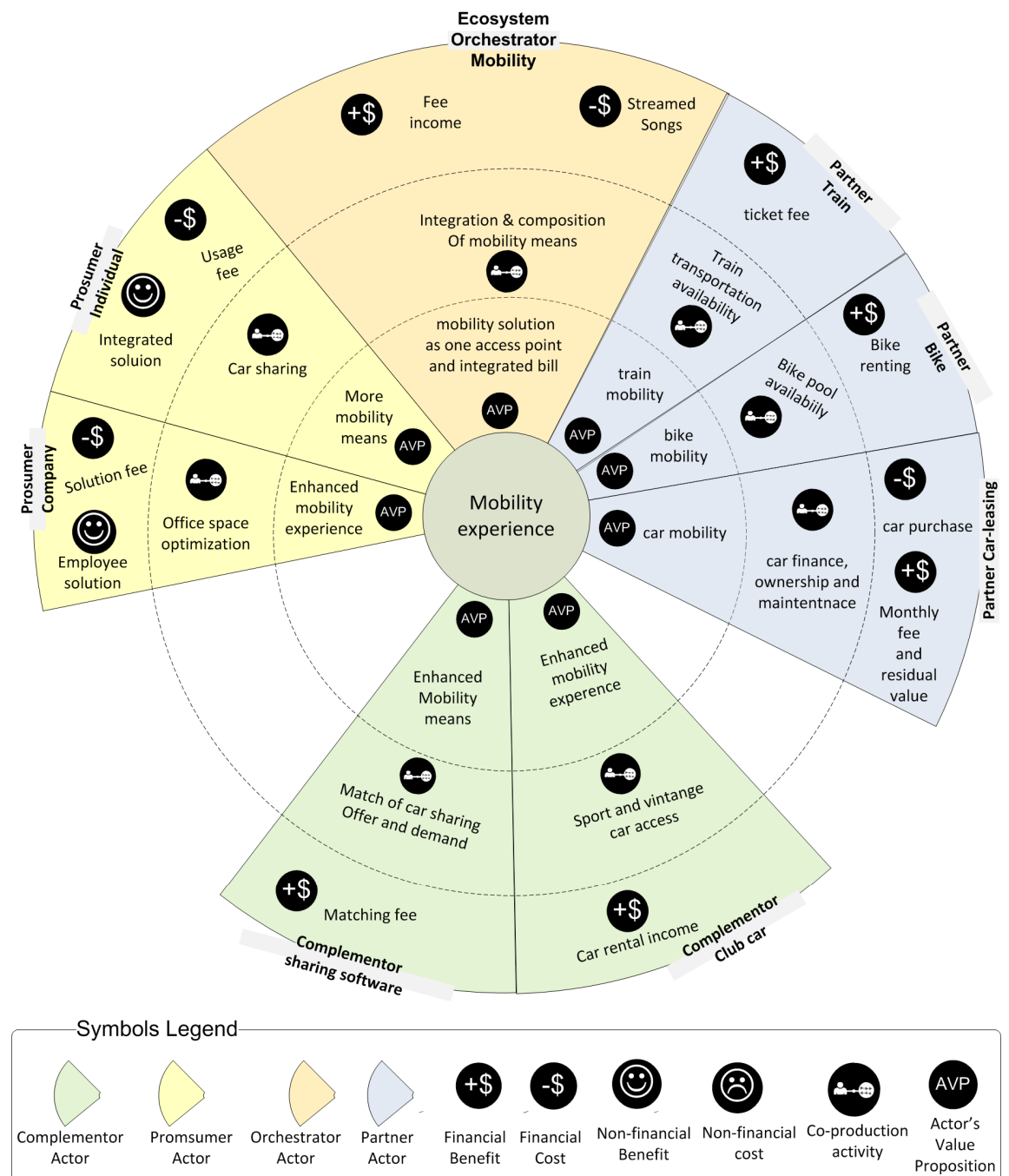

Fig. 3. The Service-Dominant Ecosystem in Mobility 
i.e. provide a mobility solution. This transition is needed to satisfy the needs of contemporary customers requiring flexibility in their mobility needs. The Dutch company has more than fifty years of experience and currently operating in Belgium, France, Germany, Luxembourg, the Netherlands, Poland, Portugal and Spain. The company belongs to a Dutch asset-finance group present in 35 countries with a lease portfolio of $€ 23.3$ billion and 4,965 employees.

In Figure 3, we show the mobility ecosystem derived from a Service-Dominant strategy applied with the mobility transformation team of the company. The inner circle shows the co-creation goal of ecosystem: mobility experience. The actors of the ecosystem include the mobility orchestrator as the new role of the company. Partners provide different mobility means in form of bikes, train trips and cars. The prosumers are individuals participate actively by sharing cars and companies that participate by optimizing the location of the employees according to their mobility needs. The complementors sharing software and car club participate respectively by offering extended mobility means and enhancing the mobility experience.

The tool let us to identify the power of network effects within the ecosystem. For instance, the sharing mechanism acts as a same-side effect by bringing more mobility means to other individuals. An example of a cross-side network effect is the benefit by the car club to individuals thanks to an enhanced mobility experience. Nowadays, the car-leasing company understands the need of other ecosystem actors to achieve their mobility goal. Moreover, the company understands that the value is no longer in the car, but in the mobility experience driven by the ecosystem.

\section{Conclusions and Future Work}

In this paper we discussed the Service-Dominant Ecosystem as a tool to design an ecosystem around the value-in-use concept. In a nutshell, the Service Dominant Ecosystem facilitates the understanding of the collaboration of different actors by brining different value propositions to form a product-service system. This system integrates value propositions form different kinds of actors. We applied our tool to the well-known example of Spotify and then we discussed the lesson we learned by using our tool in the car-leasing domain, supporting a company in the transition from product- to service-focus.

The Service-Dominant ecosystem brings a holistic perspective on the business by visualizing it at the network level in which the company participates. This holistic view enables focusing on the collaboration and the different value propositions of each actor, rather than just the internal value chain. Hence, the service-dominant ecosystem leads to new business opportunities in collaboration with others business actors to co-create value. Moreover, the tool facilitates the identification of the network effects. These are usually harder to realize when focusing solely on the internal value chain of a company.

As future work, we are further testing the ecosystem tool with practitioners and use the ecosystem to identify new business models. Moreover, we will further elaborate the mobility ecosystem and identify new business models to help the car-leasing company transitioning towards mobility. We will also focus on the mapping between the ecosystem and the technological landscape to execute the service orchestrations identified within the ecosystem. 


\section{References}

1. Neely, A.: The Servitization of Manufacturing: an Anlsysis of Global Trends. In: 14th European Operations Management Association (2007)

2. Wise, R., Baumgartner, P.: Go Downstream: The New Profit Imperative in Manufacturing. Harvard Business Review 77, 133-141 (1999)

3. Mont, O.: Drivers and barriers for shifting towards more service-oriented businesses: Analysis of the PSS field and contributions from Sweden. The Journal of Sustainable Product Design 2, 89-103 (2002)

4. Vandermerwe, S., Rada, J.: Servitization of business: Adding value by adding services. European Management Journal 6, 314-324 (1988)

5. Baines, T.S., Lightfoot, H.W., Benedettini, O., Kay, J.M.: The servitization of manufacturing: a review of literature and reflection on future challenges. Journal of Manufacturing Technology Management 20, 547-567 (2009)

6. Ostrom, A.L., Bitner, M.J., Brown, S.W., Burkhard, K.A., Goul, M., Smith-Daniels, V., Demirkan, H., Rabinovich, E.: Moving Forward and Making a Difference: Research Priorities for the Science of Service. Journal of Service Research 13, 4-36 (2010)

7. Lüftenegger, E., Grefen, P., Weisleder, C.: The Service Dominant Strategy Canvas: Towards Networked Business Models. In: Camarinha-Matos, L.M., Xu, L., Afsarmanesh, H. (eds.) PRO-VE 2012. IFIP AICT, vol. 380, pp. 207-215. Springer, Heidelberg (2012)

8. Lüftenegger, E., Grefen, P., Weisleder, C.: The Service Dominant Strategy Canvas: Defining and Visualizing a Service Dominant Strategy Through the Traditional Strategic Lens. Eindhoven University of Technology (2012)

9. Hefley, B., Murphy, W., Lusch, R.F., Vargo, S.L.: The Service-Dominant Mindset. In: Hefley, B., Murphy, W. (eds.) Service Science, Management and Engineering Education for the 21st Century, pp. 89-96. Springer, US (2008)

10. Lusch, R.F., Vargo, S.L., O’Brien, M.: Competing through service: Insights from servicedominant logic. Journal of Retailing 83, 5-18 (2007)

11. Baines, T.S., Lightfoot, H.W., Evans, S., Neely, A., Greenough, R., Peppard, J., Roy, R., Shehab, E., Braganza, A., Tiwari, A., Alcock, J.R., Angus, J.P., Bastl, M., Cousens, A., Irving, P., Johnson, M., Kingston, J., Lockett, H., Martinez, V., Michele, P., Tranfield, D., Walton, I.M., Wilson, H.: State-of-the-art in product-service systems. Proceedings of the Institution of Mechanical Engineers, Part B: Journal of Engineering Manufacture 221, 1543-1552 (2007)

12. Davies, A., Brady, T., Hobday, M.: Charting a Path Toward Integrated Solutions. MIT Sloan Management Review 43, 39-48 (2006)

13. Wieland, H., Polese, F., Vargo, S.L., Lusch, R.F.: Toward a Service (Eco) Systems Perspective on Value Creation. International Journal of Service Science, Management, Engineering, and Technology (IJSSMET) 3, 12-25 (2012)

14. Vargo, S.L., Lusch, R.F.: It's all B2B...and beyond: Toward a systems perspective of the market. Industrial Marketing Management 40, 181-187 (2011)

15. Thomas Eisenmann, G.P., Van Alstyne, M.: Strategies for Two- Sided Markets. Harvard Business Review (2006) 